\title{
An experiment to improve the capability of the regional climate model RegCM4.5 to simulate the land surface climate in dense vegetation areas
}

\author{
Minghao Yang ${ }^{1}$, Ruiting Zuo ${ }^{1, *}$ (®), Ligiong $\mathrm{WAnG}^{1,2}$, Fengliang Hu ${ }^{3}$, \\ ChaO $\mathrm{WANG}^{4}$ and $\mathrm{WeI} \mathrm{GE}^{4}$ \\ ${ }^{1}$ College of Meteorology and Oceanography, National University of Defense Technology, Nanjing 211 101, People's \\ Republic of China. \\ ${ }^{2}$ Nanjing Star-Jelly Environmental Consultants Co. Ltd, Nanjing 210 013, People's Republic of China. \\ ${ }^{3}$ No. 95871 Army of PLA, Hengyang 421 000, People's Republic of China. \\ ${ }^{4}$ Xinyang Environmental Monitoring Station, Xinyang 464 000, People's Republic of China. \\ *Corresponding author.e-mail: zuoruiting_dw@126.com
}

MS received 27 November 2018; revised 8 April 2019; accepted 13 April 2019; published online 5 July 2019

The capability of the regional climate model RegCM4.5 to simulate land surface climate in dense vegetation areas is improved by changing the empirical parameter $\alpha$ in the canopy interception coefficient in the Community Land Model, version 4.5 (CLM4.5). It is found that $\alpha$ is a very important and sensitive parameter. After increasing the value of $\alpha$, the simulation biases of latent and sensible heat flux in the wet season as well as the evaporation of intercepted water from the vegetation canopy $\left(E_{\mathrm{c}}\right)$ and vegetation transpiration $\left(E_{\mathrm{t}}\right)$ are significantly reduced. In addition, the simulated $2 \mathrm{~m}$ air temperature and surface run-off in the wet season are improved obviously. However, surface soil moisture and temperature are not sensitive to the change of $\alpha$. When regional climate simulation is conducted by RegCM4.5, the value of $\alpha$ can be increased to 0.5 if the annual average sum of the leaf area index and the stem area index is more than 2.5, which could enhance the capability of the model, to a certain extent, to simulate the land surface climate.

Keywords. Regional climate; RegCM4.5; canopy interception; vegetation transpiration; latent heat flux; CLM4.5.

\section{Introduction}

The land surface process is an important physical process affecting the energy balance and water circulation of the earth climate system. There is a constant exchange of momentum, energy and substances between land surface and atmosphere (Pielke and Avissar 1990; Zhu and Zeng 2015), which has different scales of interaction (Charney 1975). However, due to lack of observation data and the complex and variable underlying surface, it is one of the difficulties in the climate simulation study to accurately describe the physical process of the land surface. The vegetation on the land surface can not only characterise the interface between land and atmosphere interactions (Zeng et al. 2014), but also affect the atmosphere by changing the albedo (Thomas and Rowntree 1992), roughness (Notaro and Liu 2008) and evapotranspiration (ET) (Dickinson and Kennedy 1992; Chen et al. 2012) of the underlying surface. In addition, the evaporation of intercepted water from 
the vegetation canopy $\left(E_{\mathrm{c}}\right)$ is an important part of ET and water cycle (Massman 1983; Keim and Skaugset 2004), which can account for $25 \%$ of the annual precipitation in humid forest areas (Muzylo et al. 2009) and modify the land-atmosphere moisture and energy balance (Zeng et al. 2000). As a carrier of the latent heat flux (Wang and Dickinson 2012), the $E_{\mathrm{c}}$ transports water and energy to the atmosphere, affecting atmospheric dynamics and thermal processes (Seneviratne et al. 2006).

Land surface model is an indispensable part of the climate model. One of the most important and effective ways to improve the capability of land surface model to simulate the real world is to estimate the model parameters reasonably (Duan et al. 2006). Bonan et al. (2011) also pointed out that model structural errors can be compensated by parameter adjustment. Besides, Lawrence et al. (2007) found that, on the global scale, Community Land Model, version 3.0 (CLM3.0) seriously overestimates the $E_{\mathrm{c}}$. By changing the value of empirical parameter $(\alpha)$ in the interception coefficient in CLM3.0 from 1 to 0.25 , the simulation of global $E_{\mathrm{c}}$ tends to be accurate. Although their work was adopted in the Community Land Model, version 3.5 (CLM3.5) and later versions, whether the value of $\alpha(0.25)$ is reasonable at the regional scale is not known, especially in dense vegetation areas where the capability of vegetation canopy to intercept precipitation is relatively strong.

The regional climate model can better depict the regional climate characteristics with special terrain and underlying surface types. Coupling the regional climate model with the land surface model can improve the numerical simulation of the regional climate (Giorgi and Bi 2000; Christensen et al. 2001). Therefore, the regional climate model RegCM4.5 coupled with the Community Land Model, version 4.5 (CLM4.5) is used in this article. In previous studies, some scholars tried to analyse model parameters in a regional context for better simulation of land surface fluxes. For example, Zheng et al. (2002) studied the effects of vegetation change on surface energy balance and latent heat flux by analysing the vegetation coverage parameter of RegCM2. Li et al. (2014) modified the surface layer scheme by analysing the atmospheric stability parameter. In addition, Güttler et al. (2014) analysed two perturbed parameters in RegCM4.2 to study the sensitivity to planetary boundary layer parameterisation. Based on the reanalysis and observation data, we attempt to improve the capability of RegCM4.5 to simulate land surface climate in dense vegetation areas by changing the value of $\alpha$ in the interception coefficient in CLM4.5. To realise this idea, National Center for Environmental Prediction (NCEP) reanalysis data is used to drive several experiments to compare and analyse the physical variables that characterise the climate of the land surface (such as $E_{\mathrm{c}}$, vegetation transpiration $\left(E_{\mathrm{t}}\right)$, latent heat flux, sensible heat flux, $2 \mathrm{~m}$ air temperature, surface run-off, surface soil moisture, etc.) over China's Yunnan province and its surrounding areas.

\section{Methods and data}

The horizontal resolution of the experiments was $25 \mathrm{~km}$ and there was a $\sigma$ vertical coordinate system of 18 levels with the top level of $5 \mathrm{hPa}$. The centre was at $\left(30^{\circ} \mathrm{N} ; 99^{\circ} \mathrm{E}\right)$. The grid numbers in the east-west and north-south directions were 160 and 96 (the domain is shown in figure 1). The detailed physical process parameterisation schemes are the same as those of Yang et al. (2018) which suggest that the Emanuel scheme is better for cumulus convection over both land and ocean. The simulation period was 1972-2002, where the years 1972-1981 were used for the spin-up. The wet season was from May to October and the dry season was from November to April, the next year.

The canopy interception parameterisation scheme in CLM4.5 is expressed as follows:

$$
\begin{gathered}
\text { fpi }=\alpha\{1-\exp [-0.5(L+S)]\}, \\
Q=\mathrm{fpi} \times\left(q_{\text {rain }}+q_{\text {sno }}\right) .
\end{gathered}
$$

In equations, fpi represents the interception coefficient; $\alpha$ is the empirical parameter which can determine the amount of intercepted water; $L$ is the leaf area index (LAI); and $S$ is the stem area index (SAI) (figure 2 shows the global spatial distribution

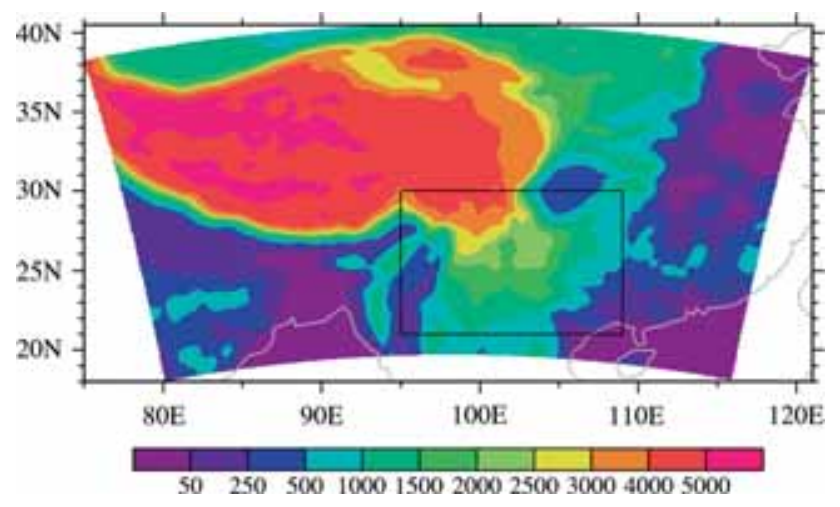

Figure 1. Model domain and terrain height (unit: $\mathrm{m}$ ). 


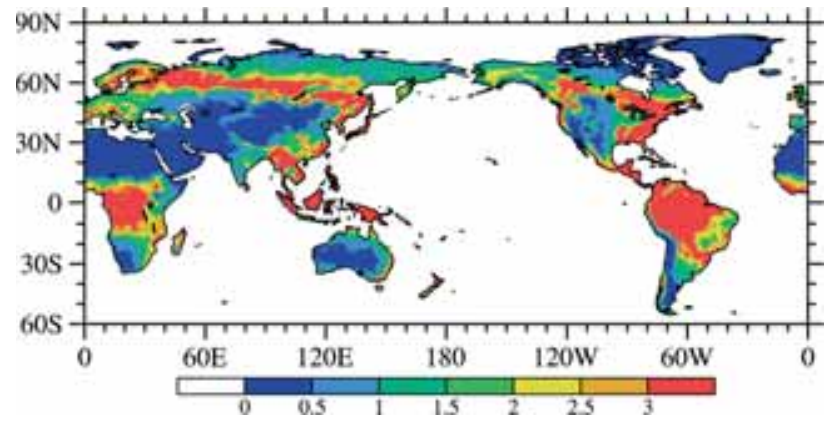

Figure 2. Spatial distribution of the annual mean sum of the LAI and the SAI.

of the sum of LAI and SAI); $Q$ is the interception by vegetation and $q_{\text {rain }}$ and $q_{\text {sno }}$ represent the amount of precipitation and snowfall per unit time, respectively. Comparing the six experiments with $\alpha$ being 0.25 (default), 0.3, 0.35, 0.4, 0.5 and 0.6 (see Appendix), we found that the simulation effect of the model on land surface climate was relatively good when $\alpha$ was 0.5 in the research area because when $\alpha$ was 0.6 , it would overestimate the capability of vegetation canopy to intercept precipitation with the less surface run-off. However, it should be pointed out that, on one hand, due to the lack of accurate observations of $E_{\mathrm{c}}$, it is necessary to indirectly verify the reasonableness of the value of $\alpha$ by other physical variables related to $E_{\mathrm{c}}$ (i.e., latent and sensible heat flux, $E_{\mathrm{t}}$, surface run-off and so on) to make the conclusion more reliable, and, on the other hand, on being limited to computing resources, we cannot give the best value of $\alpha$. In the following, the control test and the sensitive test are recorded as CTL and SEN, respectively. The only difference between them is that the values of $\alpha$ are 0.25 and 0.5 , respectively.

The initial and lateral boundary data for the model are from the NCEP reanalysis. The $0.05^{\circ}$ high resolution remote sensing data of the distribution of plant functional types (PFT) is provided by the moderate resolution imaging spectroradiometer (MODIS) (figure 3a), which is more consistent with the reality (http://www.nsii.org. cn/mapvege[2016-12-07]) than the default data (figure $3 \mathrm{~b}$ ). LAI and SAI for vegetation based on satellite phenology data that takes monthly variation into account (see figure 2) were offered by the MODIS (figure 4(a) shows the time series of mean monthly LAI and SAI over the research region). Latent and sensible heat flux were provided by Climate Forecast System Reanalysis (CFSR) (Saha et al. 2010). The $E_{\mathrm{c}}$ and $E_{\mathrm{t}}$ were given by National Oceanic and Atmospheric Administration
(NOAA) (Compo et al. 2011). The precipitation observation data CN05.1 used in this article were obtained from more than 2400 ground meteorological stations in China (Wu and Gao 2013). Surface run-off was provided by ERA-Interim. Soil moisture and temperature data in surface $10 \mathrm{~cm}$ were provided by the Global Land Data Assimilation System (GLDAS) of National Aeronautics and Space Administration (NASA).

\section{Results}

\subsection{Canopy interception evaporation}

Figure 4 shows the time series of the climatological monthly mean LAI and SAI, $E_{\mathrm{c}}$, precipitation and $E_{\mathrm{t}}$. The simulation results of $E_{\mathrm{c}}$ in CTL and SEN are less than the reanalysis and the biases are mainly concentrated in the wet season (figure 4b). This is due to the prevailing south-west warm and humid air currents over the wet season (Wang et al. 2015), so the precipitation is mainly concentrated in this period (see figure 4c). According to the reanalysis, a maximum $E_{\mathrm{c}}$ is in July, which is basically synchronised with the monthly change of precipitation, while it is in August in CTL and SEN.

Table 1 shows the means, root mean square errors (RMSEs) and biases of some land surface physical variables between the simulation results and the reanalysis. From table 1, it can be observed that there is a significant improvement of the simulated $E_{\mathrm{c}}$ in SEN compared with that in CTL. In the wet season, the biases in SEN (CTL) account for $29 \%(55 \%)$ of the mean of the reanalysis data. In addition, SEN not only has a smaller RMSE but also reduces the simulation bias by $48 \%$. The dry season is similar to the wet season. The simulation results of $E_{\mathrm{c}}$ in SEN are much closer to the reanalysis compared with CTL, but the simulated precipitation is not sensitive to the change of empirical parameter $\alpha$ (figure 4c). Maybe, it is because of the selection of cumulus parameterisation schemes. As seen from figure 4(b and c), it can be found that the smaller $E_{\mathrm{c}}$ in the model is not caused by a lack of precipitation, which indicates that the calculation scheme of the canopy maximum interception or the evaporation rate of the intercepted precipitation needs to be improved.

\subsection{Vegetation transpiration}

From figure $4(\mathrm{~d})$, it can be seen that the simulated $E_{\mathrm{t}}$ is larger than that in the reanalysis and the 

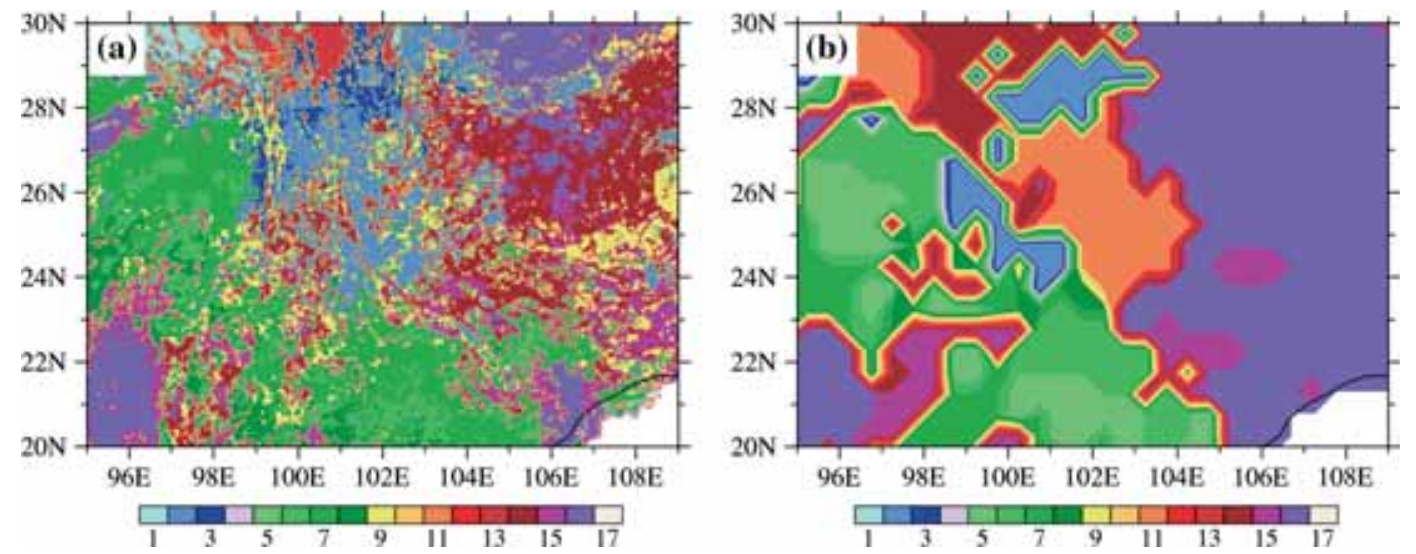

Figure 3. PFTs distribution derived from the $0.05^{\circ}$ high resolution MODIS data (a) and the default data (b) over China's Yunnan province and its surrounding areas (1: no vegetation; 2: temperate needleleaf evergreen tree; 3: boreal needleleaf evergreen tree; 4: boreal needleleaf deciduous tree; 5 : tropical broadleaf evergreen tree; 6 : temperate broadleaf evergreen tree; 7: tropical broadleaf deciduous tree; 8: temperate broadleaf deciduous tree; 9: boreal broadleaf deciduous tree; 10: temperate broadleaf evergreen shrub; 11: temperate broadleaf deciduous shrub; 12: boreal broadleaf deciduous shrub; 13: Arctic grass; 14: C3 grass; 15: C4 grass; 16: C3 rainfed crop; 17: C3 irritated crop).
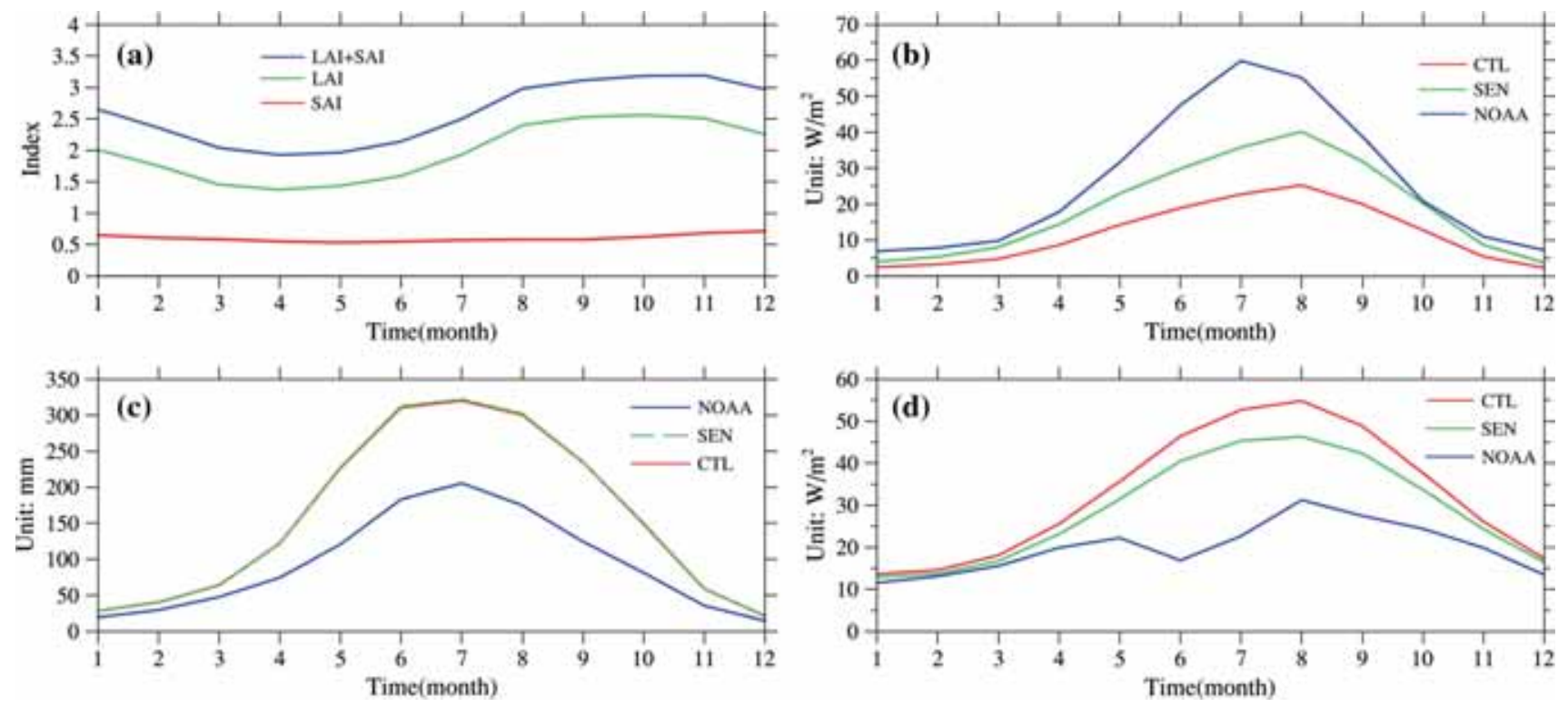

Figure 4. Time series of climatological monthly mean LAI and SAI (a), $E_{\mathrm{c}}(\mathbf{b})$, precipitation $(\mathbf{c})$ and $E_{\mathrm{t}}(\mathbf{d})$.

biases also heavily concentrate on the wet season. However, the simulation result of $E_{\mathrm{t}}$ in SEN is more consistent with that in the reanalysis. For further discussion, the parameterised expression of $E_{\mathrm{t}}$ in CLM4.5 is as follows:

$$
\begin{aligned}
E_{\mathrm{t}} & =-r_{\mathrm{dry}}^{\prime \prime} \rho_{\mathrm{atm}} \\
& \times\left[c_{\mathrm{a}}^{w} q_{\mathrm{atm}}+c_{\mathrm{g}}^{w} q_{\mathrm{g}}-\left(c_{\mathrm{a}}^{w}+c_{\mathrm{g}}^{w}\right)\left(q_{\mathrm{sat}}^{T_{\mathrm{v}}}+\frac{\mathrm{d} q_{\mathrm{sat}}^{T_{\mathrm{v}}}}{\mathrm{d} T_{\mathrm{v}}} \Delta T_{\mathrm{v}}\right)\right] \\
& \times \frac{c_{\mathrm{v}}^{h}}{c_{\mathrm{a}}^{w}+c_{\mathrm{v}}^{w}+c_{\mathrm{g}}^{w}},
\end{aligned}
$$

where $\rho_{\text {atm }}$ is the air density, $q_{\text {atm }}$ and $q_{\mathrm{g}}$ are the specific humidity at reference height and ground, respectively, $T_{\mathrm{v}}$ represents the canopy temperature and $q_{\mathrm{sat}}^{T_{\mathrm{v}}}$ is the saturation specific humidity of $T_{\mathrm{v}}$.

$r_{\mathrm{dry}}^{\prime \prime}, c_{\mathrm{a}}^{w}, c_{\mathrm{g}}^{w}, c_{\mathrm{v}}^{w}$ and $c_{\mathrm{v}}^{h}$ are resistance terms, where $c_{\mathrm{v}}^{w}$ and $c_{\mathrm{v}}^{h}$ are functions of LAI and SAI, respectively. It is found that, compared with CTL, the $T_{\mathrm{v}}$ and $q_{\mathrm{sat}}^{T_{\mathrm{v}}}$ in SEN are smaller and the $q_{\mathrm{atm}}$ is larger, while the change of $\rho_{\text {atm }}$ and $q_{\mathrm{g}}$ is not obvious, which results in the decrease of $E_{\mathrm{t}}$ in SEN.

From table 1, the RMSE and bias of $E_{\mathrm{t}}$ in both wet and dry seasons in SEN are smaller than that in CTL. SEN reduces the simulation bias by $28 \%$ 
Table 1. Means, RMSEs and biases of some land surface physical variables between the simulation results and the reanalysis in wet (dry) season (the evaporation of intercepted water from the vegetation canopy ( $E_{c}$, unit: $\left.W / m^{2}\right)$, vegetation transpiration $\left(E_{t}\right.$, unit: $\left.W / m^{2}\right)$, latent heat flux and sensible heat flux (unit: $\left.W / m^{2}\right), 2 m$ air temperature (unit: ${ }^{\circ} \mathrm{C}$ ), surface $10 \mathrm{~cm}$ soil moisture content, surface soil temperature (unit: ${ }^{\circ} \mathrm{C}$ ), surface run-off (unit: $\left.\mathrm{mm} / \mathrm{month}\right)$ ).

\begin{tabular}{|c|c|c|c|c|c|c|c|}
\hline & \multicolumn{2}{|c|}{ RMSE } & \multicolumn{3}{|c|}{ Mean } & \multicolumn{2}{|c|}{ Bias } \\
\hline & CTL & SEN & CTL & SEN & Reanalysis & CTL & SEN \\
\hline$E_{\mathrm{c}}$ & $23.4(5.7)$ & $12.3(2.9)$ & $18.9(4.5)$ & $30.0(7.4)$ & $42.3(10.1)$ & $-23.4(-5.6)$ & $-12.2(-2.7)$ \\
\hline$E_{\mathrm{t}}$ & $21.8(3.9)$ & $15.8(2.6)$ & $46.0(19.3)$ & $39.9(17.9)$ & $24.2(15.6)$ & $21.7(3.7)$ & $15.7(2.3)$ \\
\hline Latent heat flux & $4.4(6.4)$ & $2.7(5.8)$ & $96.5(46.3)$ & $99.7(47.1)$ & $100.2(52.0)$ & $-3.8(-5.7)$ & $-0.5(-4.9)$ \\
\hline Sensible heat flux & $9.3(6.8)$ & $7.4(6.3)$ & $33.5(40.0)$ & $31.3(39.5)$ & $24.7(33.5)$ & $8.8(6.5)$ & $6.6(6.0)$ \\
\hline $2 \mathrm{~m}$ air temperature & $0.93(0.78)$ & $0.84(0.76)$ & $18.2(8.6)$ & $18.0(8.6)$ & $17.2(7.8)$ & $1.01(0.76)$ & $0.83(0.73)$ \\
\hline Surface soil moisture & $0.07(0.08)$ & $0.06(0.08)$ & $0.41(0.36)$ & $0.40(0.36)$ & $0.34(0.28)$ & $0.07(0.08)$ & $0.06(0.08)$ \\
\hline Surface soil temperature & $0.35(1.20)$ & $0.34(1.21)$ & $22.2(14.7)$ & $22.2(14.7)$ & $21.9(13.5)$ & $0.33(1.18)$ & $0.32(1.19)$ \\
\hline Surface run-off & $5.0(4.0)$ & $4.5(3.7)$ & $46.8(8.4)$ & $46.2(8.1)$ & $46.1(4.6)$ & $0.7(3.8)$ & $0.1(3.5)$ \\
\hline
\end{tabular}
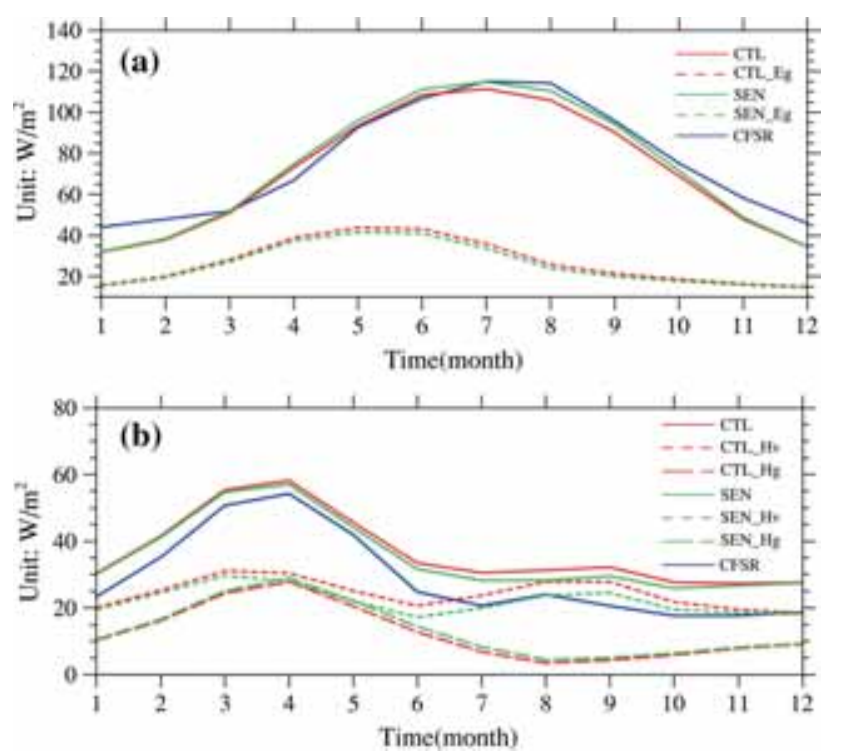

Figure 5. Time series of climatological monthly mean (a) latent heat flux and (b) sensible heat flux (CTL_Eg (SEN_Eg) is the surface evaporation of CTL (SEN), CTL_Hv (SEN_Hv) is the vegetation sensible heat flux of CTL (SEN), CTL_Hg (SEN_Hg) is the surface sensible heat flux of CTL $(\mathrm{SEN}))$.

$(38 \%)$ in the wet (dry) season compared with CTL, indicating that SEN improves the ability of CLM4.5 to simulate $E_{\mathrm{t}}$. However, as seen in figure $4(\mathrm{~d})$, the model fails to characterise the fine structure of $E_{\mathrm{t}}$ in the wet season, namely, $E_{\mathrm{t}}$ in June is smaller than that in May and July.

\subsection{Latent heat flux}

Figure 5 shows the time series of the climatological monthly mean latent heat flux and sensible heat flux. It can be observed from figure 5(a) that the bias of latent heat flux is mainly concentrated in the dry season from November to February. In addition, the simulation result of the latent heat flux in SEN is larger than that in CTL. Next, the incremental source of the latent heat flux in SEN is explored. Considering the latent heat flux is the sum of $E_{\mathrm{c}}, E_{\mathrm{t}}$ and surface evaporation (Wang and Dickinson 2012), the parameterised expression of surface evaporation $\left(E_{\mathrm{g}}\right)$ in CLM4.5 is given as follows:

$$
E_{\mathrm{g}}=-\frac{\beta_{\mathrm{soi}} \rho_{\mathrm{atm}}\left(q_{\mathrm{atm}}-q_{\mathrm{g}}\right)}{r_{\mathrm{aw}}},
$$

where $\beta_{\text {soi }}$ is an empirical function of soil water (Sakaguchi and Zeng 2009) and $r_{\text {aw }}$ represents the aerodynamic resistance. The $q_{\mathrm{atm}}$ increases and $q_{\mathrm{g}}$ is almost unchanged in SEN, because of which the specific humidity gradient between the surface and the reference atmosphere decreases. The change in $\rho_{\text {atm }}$ and $\beta_{\text {soi }}$ is not obvious. Therefore, the $E_{\mathrm{g}}$ in SEN is smaller than that in CTL (see figure 5a). So, it can be seen from equation (5) that the increment of the latent heat flux is from $E_{\mathrm{c}}$ :

$$
E \uparrow=E_{\mathrm{c}} \uparrow+E_{\mathrm{t}} \downarrow+E_{\mathrm{g}} \downarrow .
$$

As seen from table 1, the RMSE and bias of the latent heat flux in SEN are smaller than that in CTL. Compared with CTL, SEN reduces the simulation bias by $87 \%$ in the wet season and $14 \%$ in the dry season, which means the simulated latent heat flux in the wet season in SEN improved significantly. 


\subsection{Sensible heat flux}

From figure 5(b), it can be seen that the simulated sensible heat flux in SEN is smaller than that in CTL. Considering the response rate between the $E_{\mathrm{c}}$ and the atmosphere is the fastest among the components of the latent heat flux (followed by $E_{\mathrm{g}}$, with $E_{\mathrm{t}}$ being the slowest) (Lawrence et al. 2007), the $E_{\mathrm{c}}$ and the latent heat flux in SEN are relatively large, making the land surface in SEN lose heat, as the temperature drops and the sensible heat flux decreases. The sensible heat flux $(H)$ provided by the land to the atmosphere is composed of two parts: vegetation sensible heat flux $\left(H_{\mathrm{v}}\right)$ and surface sensible heat flux $\left(H_{\mathrm{g}}\right)$. The $H_{\mathrm{v}}$ and $H_{\mathrm{g}}$ parameterisation schemes in CLM4.5 are expressed as follows:

$$
\begin{aligned}
H_{\mathrm{v}}= & -\rho_{\mathrm{atm}} C_{p}\left[c_{\mathrm{a}}^{h} \theta_{\mathrm{atm}}+c_{\mathrm{g}}^{h} T_{\mathrm{g}}-\left(c_{\mathrm{a}}^{h}+c_{\mathrm{g}}^{h}\right) T_{\mathrm{v}}\right] \\
& \times \frac{c_{\mathrm{v}}^{h}}{c_{\mathrm{a}}^{h}+c_{\mathrm{v}}^{h}+c_{\mathrm{g}}^{h}}, \\
H_{\mathrm{g}}= & -\rho_{\mathrm{atm}} C_{p}\left[c_{\mathrm{a}}^{h} \theta_{\mathrm{atm}}+c_{\mathrm{v}}^{h} T_{\mathrm{v}}-\left(c_{\mathrm{a}}^{h}+c_{\mathrm{g}}^{h}\right) T_{\mathrm{g}}\right] \\
& \times \frac{c_{\mathrm{g}}^{h}}{c_{\mathrm{a}}^{h}+c_{\mathrm{v}}^{h}+c_{\mathrm{g}}^{h}},
\end{aligned}
$$

where $c_{\mathrm{a}}^{h}, c_{\mathrm{g}}^{h}$ and $c_{\mathrm{v}}^{h}$ are resistance terms and $C_{p}$ is the specific heat capacity of air $\left(\mathrm{J} \mathrm{kg}^{-1} \mathrm{~K}^{-1}\right)$. Because the change of $T_{\mathrm{v}}$ is more obvious than the other variables, the decrease of $T_{\mathrm{v}}$ results in the reduction of $H_{\mathrm{v}}$ and the increase of $H_{\mathrm{g}}$ in SEN compared with CTL. From equation (8), it can be seen that the decrease in $H$ is caused by the reduction of $H_{\mathrm{v}}$ :

$$
H \downarrow=H_{\mathrm{v}} \downarrow+H_{\mathrm{g}} \uparrow .
$$

From table 1, it can be found that the RMSE is relatively small in SEN. In addition, SEN reduces the simulation bias by $25 \%(8 \%)$ in the wet (dry) season compared with CTL. In general, SEN improves the ability of the model to simulate the sensible heat flux over Yunnan and its surrounding areas.

The above analyses show that in terms of annual average, the $E_{\mathrm{c}}$ and $E_{\mathrm{t}}$ in CTL (SEN) account for $25.5 \%(16.4 \%)$ and $39.4 \%(45.7 \%)$ of the total latent heat flux, respectively, while these are $34.4 \%$ and $26.1 \%$ in the reanalysis. In addition, the Bowen ratio in the wet (dry) season in CTL, SEN and the reanalysis are $0.35(0.86), 0.31(0.84)$ and 0.25 (0.64). It can be found that, in both wet season and dry season, the simulated Bowen ratio is larger than that in the reanalysis, which indicates that the distribution of the heat flux between the sensible heat flux and the latent heat flux in the model is still a big problem in the research area. This would lead to the corresponding change of the distribution of the moist static energy, atmospheric stratification and vertical movement (Zheng et al. 2002), so it may also be one of the sources of the simulation error of the atmospheric circulation in this coupling model.

\subsection{Other physical variables}

As seen from table 1, the simulation results of the soil moisture and temperature in surface $10 \mathrm{~cm}$ in CTL and SEN are basically consistent, indicating that these two variables are not sensitive to the change of empirical parameters $\alpha$. In terms of surface run-off, it can be found that the simulation result in CTL is larger than that in the reanalysis. However, because of the stronger capability of the canopy to intercept precipitation in SEN, which reduces the amount of surface run-off produced by precipitation, the bias in SEN is smaller than that in CTL. In addition, the RMSE and biases of $2 \mathrm{~m}$ air temperature in SEN are smaller than that in CTL, especially in the wet season where the simulation deviation decreases by $18 \%$. It shows that, compared with CTL, there is some improvement with regard to the simulation of the surface run-off and $2 \mathrm{~m}$ air temperature in SEN, especially in the wet season.

\section{Conclusions}

The NCEP reanalysis data during the period 1972-2002 is used in this article to drive the regional climate model RegCM4.5 coupled with the land surface model CLM4.5. Several experiments are designed by adjusting the empirical parameter in the canopy interception coefficient in CLM4.5 over China's Yunnan province and its surrounding areas. Based on the reanalysis and observation data, some physical variables in different experiments related to land surface state, like the evaporation of intercepted water, vegetation transpiration, latent heat flux, sensible heat flux, $2 \mathrm{~m}$ air temperature, soil moisture content and surface run-off, are compared and analysed to attempt to improve the value of the empirical parameter in areas with dense vegetation. We find that after 
changing that parameter from 0.25 to 0.5 , the ability of the model to simulate land surface climate is improved obviously. The main conclusions are as follows.

RegCM4.5 can well simulate the latent and sensible heat flux, $2 \mathrm{~m}$ air temperature, surface run-off and surface soil temperature over Yunnan province and its surrounding areas. However, the performance of the model is unsatisfactory on simulating $E_{\mathrm{c}}, E_{\mathrm{t}}$ and surface soil moisture. Compared with the reanalysis data, the simulated $E_{\mathrm{c}}$ is smaller, while $E_{\mathrm{t}}$ and surface soil moisture are larger. In addition, the simulation biases of $E_{\mathrm{c}}$ and $E_{\mathrm{t}}$ are mainly concentrated on the wet season.

After increasing the value of the empirical parameter in the canopy interception coefficient in CLM4.5, there is a significant reduction of biases in simulating latent heat flux and sensible heat flux in wet season as well as $E_{\mathrm{c}}$ and $E_{\mathrm{t}}$. Besides, the improvement to simulate $2 \mathrm{~m}$ air temperature and surface run-off in the wet season is also relatively obvious. However, the surface soil moisture and temperature are not sensitive to the change of this parameter.

The change of the empirical parameter in the interception coefficient can significantly impact the capability of RegCM4.5 to simulate land surface climate in dense vegetation areas. It is a very sensitive and important parameter. When regional climate simulation is conducted by using RegCM4.5, the value of $\alpha$ can be increased to 0.5 if the annual average sum of LAI and SAI is more than 2.5, which could enhance the capability of the model, to a certain extent, to simulate the land surface state.

\section{Acknowledgements}

We are thankful to Dr Xiong Chen and Dr Peilong $\mathrm{Yu}$ for the valuable discussions. This research was supported by the National Natural Science Foundation of China (41475071).

\section{Appendix}

Table A1. Annual means, RMSEs and biases of the latent heat flux and sensible heat flux (unit: $W / m^{2}$ ), surface run-off (unit: $\mathrm{mm} /$ month) and $2 \mathrm{~m}$ air temperature (unit: ${ }^{\circ} \mathrm{C}$ ) between RegCM4.5 and the reanalysis over China's Yunnan province and its surrounding areas with different empirical parameters (0.25 (CTL), 0.3 (SEN0.3), 0.35 (SEN0.35), 0.4 (SEN0.4), 0.5 (SEN0.5) and 0.6 (SEN0.6)) in the interception coefficient in CLM4.5.

\begin{tabular}{|c|c|c|c|c|c|c|}
\hline & CTL & SEN0.3 & SEN0.35 & SEN0.4 & SEN0.5 & SEN0.6 \\
\hline \multicolumn{7}{|c|}{ Latent heat flux } \\
\hline RMSE & 29.4 & 29.4 & 29.4 & 29.4 & 29.5 & 29.5 \\
\hline Mean & 96.5 & 97.1 & 97.8 & 98.4 & 99.7 & 101.0 \\
\hline Bias & -3.8 & -3.1 & -2.4 & -1.8 & -0.5 & 0.7 \\
\hline \multicolumn{7}{|c|}{ Sensible heat flux } \\
\hline RMSE & 20.1 & 19.9 & 19.7 & 19.6 & 19.4 & 19.3 \\
\hline Mean & 33.5 & 33.0 & 32.5 & 32.1 & 31.3 & 30.6 \\
\hline Bias & 8.8 & 8.3 & 7.8 & 7.4 & 6.6 & 5.9 \\
\hline \multicolumn{7}{|c|}{ Surface run-off } \\
\hline RMSE & 5.0 & 4.9 & 4.8 & 4.7 & 4.5 & 4.4 \\
\hline Mean & 46.8 & 46.7 & 46.6 & 46.5 & 46.2 & 45.9 \\
\hline Bias & 0.7 & 0.6 & 0.5 & 0.4 & 0.1 & -0.2 \\
\hline \multicolumn{7}{|c|}{$2 m$ air temperature } \\
\hline RMSE & 0.93 & 0.91 & 0.89 & 0.87 & 0.84 & 0.81 \\
\hline Mean & 18.17 & 18.15 & 18.13 & 18.11 & 18.07 & 18.04 \\
\hline Bias & 0.92 & 0.90 & 0.88 & 0.86 & 0.83 & 0.80 \\
\hline
\end{tabular}




\section{References}

Bonan G B, Lawrence P J, Oleson K W, Levis S, Jung M, Reichstein M, Lawrence D M and Swenson S C 2011 Improving canopy processes in the community land model version 4 (CLM4) using global flux fields empirically inferred from FLUXNET data; J. Geophys. Res. 116 G02014.

Charney J G 1975 Dynamics of deserts and drought in the Sahel; Quart. J. Roy. Meteorol. Soc. 101 193-202.

Chen G, Notaro M and Liu Z 2012 Simulated local and remote biophysical effects of afforestation over Southeast United States in boreal summer; J. Clim. 25 4511-4522.

Christensen O B, Gaertner M A, Prego J A and Polcher J 2001 Internal variability of regional climate models; Clim. Dyn. $17875-887$.

Compo G P, Whitaker J S and Sardeshmukh P D 2011 Review article: The twentieth century reanalysis project; Quart. J. Roy. Meteorol. Soc. 137 1-28.

Dickinson R E and Kennedy P 1992 Impacts on regional climate of Amazon deforestation; Geophys. Res. Lett. 19 1947-1950.

Duan Q Y, Schaakeb J, Andreassian V, Franks S, Goteti G, Gupta H V, Gusev Y M, Habets F, Hall A, Hay L, Hogue T, Huang M, Leavesley G, Liang X, Nasonova O N, Noilhan J, Oudin L, Sorooshian S, Wagener T and Wood E F 2006 Model parameter estimation experiment (MOPEX): An overview of science strategy and major results from the second and third workshops; J. Hydrol. 320 3-17.

Giorgi F and Bi X 2000 A study of internal variability of a regional climate model; J. Geophys. Res. 105 29,503-29,521.

Güttler I, Branković Č, O'Brien T A, Coppola E, Grisogono B and Giorgi F 2014 Sensitivity of the regional climate model RegCM4.2 to planetary boundary layer parameterization; Clim. Dyn. 44 2249-2265.

Keim R F and Skaugset A E 2004 A linear system model of dynamic through fall rates beneath forest canopies; Water Resour. Res. 40 W05208.

Lawrence D M, Thornton P E, Oleson K and Bonan G B 2007 The partitioning of evapotranspiration into transpiration, soil evaporation, and canopy evaporation in a GCM: Impacts on land-atmosphere interaction; J. Hydrometeorol. 8 862-880.

Li S, Zhong Z, Guo W and Lu W 2014 Modifications on the surface layer scheme in RegCM4.3.5-CLM; Clim. Dyn. 44 2249-2265.

Corresponding editor: Subimal Ghosh
Massman W J 1983 The derivation and validation of a new model for the interception of rainfall by forests; J. Agric. Meteorol. 28 261-286.

Muzylo A, Llorens P, Valente F, Keizer J J, Domingo F and Gash J H C 2009 A review of rainfall interception modelling; J. Hydrol. 370 191-206.

Notaro M and Liu Z Y 2008 Joint statistical and dynamical assessment of simulated vegetation feedbacks on climate over the boreal forests; Clim. Dyn. 31 691-712.

Pielke R A and Avissar R 1990 Influence of landscape structure on local and regional climate; Landscape Ecol. 4 133-155.

Saha S et al. 2010 The NCEP climate forecast system reanalysis; Bull. Am. Meteor. Soc. 91 1015-1057.

Sakaguchi K and Zeng X 2009 Effects of soil wetness, plant litter, and under-canopy atmospheric stability on ground evaporation in the community land model (CLM3.5); J. Geophys. Res. 114 D01107.

Seneviratne S I, Lüthi D, Litschi M and Schär C 2006 Landatmosphere coupling and climate change in Europe; Nature $443205-209$.

Thomas G and Rowntree P R 1992 The boreal forests and climate; Quart. J. Roy. Meteorol. Soc. 118 469-497.

Wang K, Dickinson R E 2012 A review of global terrestrial evapotranspiration: Observation, modeling, climatology, and climatic variability; Rev. Geophys. 50 RG2005.

Wang M, Gao X, Shi Y and Giorgi F 2015 Projection of the future drought over Yunnan and its surrounding areas by RegCM4; Plateau Meteorol. 34 706-713 (in Chinese).

Wu J and Gao X J 2013 A gridded daily observation dataset over China region and comparison with the other datasets; Chinese J. Geophys. Ch. 56 1102-1111.

Yang M, Zuo R, Wang L and Chen X 2018 Simulation of land surface climate over China with RegCM4.5: Verification and analysis; Adv. Meteorol. 2018 1-14.

Zeng N, Shuttleworth J W and Gash J H C 2000 Influence of temporal variability of rainfall on interception loss. Part I. Point analysis; J. Hydrol. 228 228-241.

Zeng X D, Li F and Song X 2014 Development of the IAP dynamic global vegetation model; Adv. Atmos. Sci. 31 505-514.

Zheng Y, Yu G and Kong Y 2002 The effects of vegetation change on regional climate II: Mechanisms; Acta Meteorol. Sin. 60 17-30 (in Chinese).

Zhu J W and Zeng X D 2015 Comprehensive study on the influence of evapotranspiration and albedo on surface temperature related to changes in the leaf area index; Adv. Atmos. Sci. 32 935-942. 